Molecules, 2002, 7, 867-870

\title{
molecules
}

ISSN 1420-3049

http://www.mdpi.org

\section{Microwave-Accelerated Iodination of Some Aromatic Amines, Using Urea-Hydrogen Peroxide Addition Compound (UHP) as the Oxidant ${ }^{\dagger}$}

\section{Maciej Sosnowski and Lech Skulski*}

Chair and Laboratory of Organic Chemistry, Faculty of Pharmacy, Medical University, 1 Banacha Street, PL 02-097 Warsaw, Poland

$\dagger$ This short paper was presented at the Sixth Electronic Conference on Synthetic Organic Chemistry (ECSOC-6, http://www.mdpi.net/ecsoc-6/), September 1-30, 2002, paper E006).

* To whom correspondence should be addressed; E-mail: 1skulski@ farm.amwaw.edu.pl; Tel./Fax: $+(48) 225720643$

Received: 15 October 2002; in revised form: 11 December 2002/ Accepted: 12 December 2002 / Published: 31 December 2002

\begin{abstract}
A fast and simple method for the oxidative iodination of some aromatic amines, under microwave irradiation, is reported, using diiodine and the the strongly $\mathrm{H}$ bonded urea-hydrogen peroxide addition compound $\left(\mathrm{H}_{2} \mathrm{NCONH}_{2} \cdots \mathrm{H}_{2} \mathrm{O}_{2}, \mathrm{UHP}\right)$ as the oxidant. The reactions were carried out in boiling $\mathrm{CHCl}_{3}$ under a reflux condenser to afford, within 10 minutes, the purified monoiodinated products in $40-80 \%$ yields.
\end{abstract}

Keywords: Monoiodinated arylamines, urea-hydrogen peroxide as oxidant, microwave irradiation 


\section{Introduction}

The use of microwave irradiation to simplify and improve classic organic reactions has become a very popular technique because it often results in shorter reaction times, higher yields and cleaner reactions [1-3]. For example, Khalaj and co-workers recently reported iodination of $N$-succinyl-4-[3,3(1,4-butanediyl)triazene]benzoate with trimethylsilyl iodide (generated in situ from trimethylsilyl chloride and regular $\mathrm{Na}^{127} \mathrm{I}$ in dry acetonitrile) at $75{ }^{\circ} \mathrm{C}$ for 45 minutes [4]. $\mathrm{N}$-Succinimidyl-4-Ibenzoate was thus prepared in $90 \%$ yield, after isolation and purification. Activation of this reaction by exposure to microwave irradiation (in a domestic oven at $2450 \mathrm{MHz}$ for 8 minutes) afforded the same pure monoiodinated product in $87 \%$ yield; in small scale preparations under the same microwave assisted conditions, but using radioactive $\mathrm{Na}^{125} \mathrm{I}$, the corresponding labelled aromatic iodide was obtained in $81 \%$ radiochemical yield. We propose, however, that this iodination method by no means belongs to the class of microwave assisted oxidative iodination reactions of aromatics that, as far as we know, are reported for the first time in this communication.

In our laboratory we have recently devised a novel (classical) method for the oxidative iodination of several aromatic amines using UHP as an effective oxidant, carrying out the reactions in neat ethyl acetate (at room temperature for 30 minutes, then at $45{ }^{\circ} \mathrm{C}$ for 23 hours) [5]. So far, we have thus obtained the following yields of purified products: 4- $\mathrm{IC}_{6} \mathrm{H}_{4} \mathrm{NH}_{2}(64 \%)$, 4- $\mathrm{IC}_{6} \mathrm{H}_{4} \mathrm{NHMe}(41 \%)$, 4- $\mathrm{IC}_{6} \mathrm{H}_{4} \mathrm{NMe}_{2}$ (85\%), 4- $\mathrm{IC}_{6} \mathrm{H}_{4} \mathrm{NEt}_{2}$ (60\%), 4-I-2- $\mathrm{MeC}_{6} \mathrm{H}_{3} \mathrm{NH}_{2}$ (92\%), 2-I-5- $\mathrm{MeC}_{6} \mathrm{H}_{3} \mathrm{NH}_{2}(62 \%)$, 2,4- $\mathrm{I}_{2} \mathrm{C}_{6} \mathrm{H}_{3} \mathrm{NH}_{2}$ (58\%), 2-Cl-4- $\mathrm{IC}_{6} \mathrm{H}_{3} \mathrm{NH}_{2}$ (55\%), and 3-Cl-4- $\mathrm{IC}_{6} \mathrm{H}_{3} \mathrm{NH}_{2}$ (43\%). All these reactions obeyed the following stoichiometry: $2 \mathrm{ArH}+\mathrm{I}_{2}+\mathrm{H}_{2} \mathrm{O}_{2} \rightarrow 2 \mathrm{ArI}+2 \mathrm{H}_{2} \mathrm{O}$.

\section{Results and Discussion}

In this work, we have attempted to accelerate the aforementioned reactions with microwave irradiation, under an externally attached reflux condenser. We have established that the best results are attained by replacing ethyl acetate (b.p. $77^{\circ} \mathrm{C}$ ) with chloroform (b.p. $61{ }^{\circ} \mathrm{C}$ ) as the solvent of choice. The reactions were complete after ca. 10 minutes. After pouring the reaction mixtures into vigorously stirred excess aqueous $\mathrm{Na}_{2} \mathrm{SO}_{3}$ solutions, the organic layers were separated, dried over $\mathrm{Na}_{2} \mathrm{SO}_{4}$, the solvent was distilled off, and the residues were recrystallized from an appropriate solvent. As expected for an oxidative aromatic iodination involving transient iodine (I) species, $\mathrm{I}^{+}$, para-iodination of the activated monosubstituted benzene substrates was observed and no traces of the potential orthoisomers were detected in the purified products, which were checked chromatographically (TLC) to establish their homogeneity, then they were microanalyzed (\%I), and their ${ }^{1} \mathrm{H}-\mathrm{NMR}$ spectra were scrutinized. Their melting points (uncorrected) were very close to those obtained with the classical method [5]. By comparing our novel results (Table 1) with those previously obtained (vide supra) it is seen that the microwave assisted iodination reactions afforded somewhat lower yields, but the previous reaction times were considerably shortened to only 10 minutes. In our opinion, these results suggest that further study of various aromatic iodination reactions under microwave irradiation is a worthwhile 
pursuit. We speculate that results would probably be better with the use of focused monomode microwave irradiation, what is unfortunately not available in our laboratory.

Table 1. Final yields of the monoiodinated aromatic amines (after purification) and their melting points (uncorrected).

\begin{tabular}{|l|c|c|c|c|}
\hline Iodinated product & Yield (\%) & M. p. $\left({ }^{\mathbf{0}} \mathbf{C}\right)$ & Lit.[6] m.p. $\left({ }^{\mathbf{0}} \mathbf{C}\right)$ & $\begin{array}{c}\text { Analyses [\% I] } \\
\text { Calcd/Found }\end{array}$ \\
\hline $4-\mathrm{IC}_{6} \mathrm{H}_{4} \mathrm{NMe}_{2}$ & 80 & $80-81$ & 82 & $51.36 / 51.0$ \\
$4-\mathrm{IC}_{6} \mathrm{H}_{4} \mathrm{NH}_{2}$ & 58 & $62-63$ & $63-65$ & $57.94 / 57.5$ \\
$4-\mathrm{I}-2-\mathrm{MeC}_{6} \mathrm{H}_{3} \mathrm{NH}_{2}$ & 60 & $87-88$ & $88,91-92$ & $54.45 / 54.2$ \\
$2,4-\mathrm{I}_{2} \mathrm{C}_{6} \mathrm{H}_{3} \mathrm{NH}_{2}{ }^{a)}$ & 50 & $95-96$ & $95-96$ & $73.58 / 73.2$ \\
$2-\mathrm{Cl}-4-\mathrm{IC}_{6} \mathrm{H}_{3} \mathrm{NH}_{2}$ & 50 & $71-72$ & $68,70-73$ & $50.07 / 49.6$ \\
$3-\mathrm{Cl}-4-\mathrm{IC}_{6} \mathrm{H}_{3} \mathrm{NH}_{2}$ & 43 & $64-66$ & $64-66$ & $50.07 / 49.8$ \\
$4-\mathrm{Br}-2-\mathrm{IC}_{6} \mathrm{H}_{3} \mathrm{NH}_{2}$ & 40 & $69-70$ & $70-71$ & $42.59 / 42.2$ \\
\hline
\end{tabular}

a) synthesized from $4-\mathrm{IC}_{6} \mathrm{H}_{4} \mathrm{NH}_{2}$

\section{Experimental}

\section{General}

Our microwave experiments were performed using a microwave oven purchased from "Plazmatronika" (Wroclaw, Poland). The microwave reactor, working at $2450 \mathrm{MHz}$, consists of a multimode microwave power delivery system with an operator selectable power output between 0 and $750 \mathrm{~W}$, and a tube allowing an external reflux condenser to be attached. The reactions were carried out in glass vessels $(200 \mathrm{~mL})$. All our experiments were performed using the stirring option, whereby the reaction mixtures are stirred by means of a rotating magnetic plate located below the floor of the microwave cavity and a teflon-coated magnetic stirring bar placed inside the vessel. The temperature of the vessel contents was monitored using a calibrated infrared temperature control mounted under the same. All chemicals were of reagent grade (Aldrich, Fluka), and were used without purification.

\section{Microwave-Accelerated Iodination Reactions}

UHP (1.53 g, $16.5 \mathrm{mmol}, 10 \%$ excess) and finely powdered diiodine (3.81 g, $15 \mathrm{mmol})$ were suspended in $\mathrm{CHCl}_{3}(50 \mathrm{~mL})$. Then, $30 \mathrm{mmol}$ of an appropriate arylamine was added, the mixture was placed inside the microwave cavity, a reflux condenser was attached, and the magnetic stirring was switched on. A suitable power output $(500$ to $750 \mathrm{~W}$ ) was then chosen to ensure a slight, uninterrupted reflux of the solvent. After 10 minutes, the reaction mixtures were cooled to room temperature, then they were poured into vigorously stirred aqueous $\mathrm{Na}_{2} \mathrm{SO}_{3}$ solutions $\left(5 \mathrm{~g} \mathrm{Na}_{2} \mathrm{SO}_{3}\right.$ in $50 \mathrm{~mL}$ of water). 
The organic hyers were separated, dried over anhydrous $\mathrm{Na}_{2} \mathrm{SO}_{4}$, filtered, and the solvent was distilled off. The residues were cooled, if they were oily, until they solidified, and then they were recrystallized from hexane, or, in the case of $4 \mathrm{IC}_{6} \mathrm{H}_{4} \mathrm{NMe}_{2}$, from $\mathrm{EtOH}$. The final results are shown in Table 1. The purities and homogeneities of the purified products were checked by TLC, ${ }^{1} \mathrm{H}-\mathrm{NMR}$ spectroscopy and microanalyses (\%I). The observed (uncorrected) m.ps. were very close to those reported in our earlier work [5].

\section{References}

1. Microwave-Enhanced Chemistry Fundamentals, Sample Preparation and Applications. Kingston, H. M.; Haswell, S. J., Eds.; American Chemical Society: Washington, D.C., 1997.

2. Perreux, L.; Loupy, A. A tentative realization of microwave effects in organic synthesis according to the reaction medium, and mechanistic considerations. Tetrahedron 2001, 57, 9199 - 9223 (a review).

3. Lindstroem, P.; Tierney, J.; Whathey, B.; Westman, J. Microwave assisted organic synthesis - a review. Tetrahedron 2001, 57, 9225 - 9283.

4. Khalaj, A.; Beiki, D., Rafiee, H.; Najafi, R. A New and Simple Synthesis of $N$-Succinimidyl-4$\left[{ }^{127 / 125} \mathrm{I}\right]$ Iodobenzonate Involving a Microwave-Accelerated Iodination Step. J. Labelled Cpd. Radiopharm. 2001, 44, 235-240.

5. Lulinski, P.; Kryska, A.; Skulski, L. unpublished results, reported at the International Symposium on Frontiers in Molecular Science 2002, July 14-18, Qingdao, China; see Proceedings, p. 23, in press.

6. Dictionary of Organic Compounds. $6^{\text {th }}$ ed.; Chapman \& Hall: London 1996.

Sample Availability: Available from the authors.

(C) 2002 by MDPI (http://www.mdpi.org). Reproduction is permitted for noncommercial purposes. 